\title{
Adhesion between oppositely charged polyelectrolytes in salt solution
}

Latifah Alfhaid, ${ }^{1,2}$ Nicholas H. Williams, ${ }^{3}$ and Mark Geoghegan ${ }^{1, \#}$

${ }^{1}$ Department of Physics and Astronomy, University of Sheffield, Hounsfield Road, Sheffield S3 7RH, United Kingdom, ${ }^{2}$ Department of Physics, College of Science, University of Ha'il, P.O. Box 2440, Hail, Saudi Arabia, ${ }^{3}$ Department of Chemistry, University of Sheffield, Brook Hill, Sheffield S3 7HF, United Kingdom.

\section{Correspondence to: Dr Latifah Alfhaid (E-mail: I.alfhaid@uoh.edu.sa)}

\begin{abstract}
The adhesion at the aqueous interface between a polyacid hydrogel and a grafted polycation layer (brush) is shown to be reversible on the addition of sodium chloride, which screens the charges on the gel and brush. Furthermore it is shown that a double-network hydrogel both exhibits adhesive failure and stronger adhesion with the brush than a simple poly(methacrylic acid) [PMAA] hydrogel, whereas the PMAA gel undergoes cohesive failure on detachment. The adhesive force at the hydrogel-brush interface significantly increases after adding dilute salt solution (of $0.001 \mathrm{M}$ ). Once the concentration of salt solution is raised above $0.05 \mathrm{M}$, both the adhesive force and work done in detaching both single- and doublenetwork hydrogels from the brush surface are notably reduced. This result confirms that reversible adhesion between a hydrogel and polymer brush in salt solutions is possible, although a double-network gel is required for adhesive failure.
\end{abstract}

\section{INTRODUCTION}

The use of "smart" materials,1,2 which are simultaneously responsive to changes in environmental conditions, such as $\mathrm{pH}^{3-6}$ salt, ${ }^{7}$ and temperature ${ }^{5,8-10}$ permits a new paradigm in adhesive technology, whereby the adhesion between two surfaces may be controlled. In such circumstances two surfaces can be adhered, and a change in their local environment triggers debonding. The ability to detach "on-demand" provides a different route to creating a host of products that may easily be recycled, as well as extending the capabilities of other goods. ${ }^{2,5,11}$

The use of $\mathrm{pH}$ to switch the adhesive properties of materials generally involves surfaces being adhered in water so that the addition of an acid or a base causes the bonding to fail. The first demonstration of $\mathrm{pH}$-switchable adhesion was using cationic poly[2-(dimethylamino)ethyl methacrylate] (PDMAEMA) grafted chains adhering to a hemispherical gel of poly(methacrylic acid) (PMAA), which spontaneously failed when the $\mathrm{pH}$ was reduced to less than two. ${ }^{4}$ Later experiments considering two grafted layers (brushes) of the same oppositely-charged polyelectrolytes indicated that the adhesion between the two layers was dominated by

\footnotetext{
\# Present address: School of Engineering, Newcastle University, Merz Court, Newcastle NE1 7RU, UK
} 
electrostatic forces, and that hydrogen bonding did not play a large role in the adhesion. ${ }^{12}$ Nevertheless, when one of the components is not a polyelectrolyte, hydrogen bonding can be the determining parameter in $\mathrm{pH}$-controlled switchable adhesion. ${ }^{6}$

In the case of the oppositely charged polyelectrolytes, the adhesion typically fails cohesively in water, ${ }^{13}$ limiting the scope for reuse of the couple. Strengthening the PMAA hydrogel with poly[oligo(ethylene glycol)methyl ether methacrylate] (POEGMA) to form a double-network hydrogel improved the repeatability of the adhesion, so that the couple could be mechanically detached and reattached in water. ${ }^{3}$ The second hydrogel, which is not a polyelectrolyte, imparts improved fracture resistance to the rather brittle PMMA gel. This is a characteristic feature of double-network hydrogels. ${ }^{14,15}$

The addition of salt shields the charges on the polymer chains which ultimately causes the partial collapse of both polyelectrolyte gels ${ }^{16,17}$ and brushes. ${ }^{18-20}$ Because of the proximity of their grafting points, weak polyelectrolyte brushes exhibit a rich non-monotonic $\mathrm{pH}$ - and saltdependent swelling behaviour. ${ }^{19,21}$ In particular, the degree of ionization of the brush initially increases with added salt, causing swelling. ${ }^{22}$ This is due to the requirements for electroneutrality and Donnan equilibrium inside the brush. Unlike brushes, polyelectrolyte gels can retain an ionization level similar to those of free chains in bulk solution, and such unusual effects are not observed, although polyanions in acidic solution have been observed to swell on the addition of salt. ${ }^{16}$

Although it is known that the addition of salt causes the adhesion to fail in the case of oppositely charged polyelectrolyte brushes, ${ }^{7}$ it is not immediately clear how salt interacts with a gel-brush adhesive couple of oppositely charged polyelectrolytes. The adhesive properties of PDMAEMA brushes not only depend upon the salt concentration but also on the nature of the salt, with $\mathrm{KCl}$ exhibiting a much weaker effect on adhesion than $\mathrm{KBr}$ or $\mathrm{KI} .{ }^{23}$ In the present work, the adhesion of a PMAA hydrogel or a PMAA-POEGMA double network hydrogel with a poly[2(diethylamino)ethyl methacrylate] (PDEAEMA) brush is studied as a function of $\mathrm{NaCl}$ concentration. It is shown that increasing the salt concentration does indeed cause a decrease in adhesion, although the adhesion is not a monotonic function of $[\mathrm{NaCl}]$.

\section{EXPERIMENTAL}

\section{Preparation of the single-network hydrogel}

The PMAA single-network (SN) hydrogel was prepared using free radical polymerization with water (100 $\mathrm{mL}, 5.5 \mathrm{~mol}$ ), methacrylic acid (MAA; 98\% Aldrich; $20 \mathrm{~mL}, 0.23 \mathrm{~mol}$ ), 2,2'-azobis(2-methylpropionamidine) dihydrochloride (AMPA; 98\% Aldrich; $0.03 \mathrm{~g}, 0.1 \mathrm{mmol}$ ), and $N, N^{\prime}$-methylenebisacrylamide (MBA; $99 \%$ Aldrich; $0.06 \mathrm{~g}, 0.4 \mathrm{mmol}$ ). The subsequent gel was placed in a mould in an oven at $80^{\circ} \mathrm{C}$ for $2 \mathrm{~h}$ before 
being cut into hemispherical pieces and stored under deionized water for at least three days before using them in adhesion experiments. The water was changed at least twice over this time.

\section{Preparation of the double-network hydrogel}

The PMAA-POEGMA double-network (DN) hydrogel was synthesized following an earlier methodology ${ }^{24}$ by first making the PMAA SN hydrogel and then immersing this hydrogel inside a solution of oligo(ethylene glycol)methyl ether methacrylate (OEGMA) which was also polymerized. A more densely crosslinked PMAA hydrogel from that used for the SN hydrogels was required. ${ }^{15}$ The first (PMAA) hydrogel was prepared using the same free radical polymerization method as for the SN hydrogel, but with different quantities: water ( $50 \mathrm{~mL}, 2.8 \mathrm{~mol}$ ), MAA ( $98 \%$ Aldrich; $10 \mathrm{~mL}, 0.12 \mathrm{~mol}$ ), potassium persulfate (KPS; $99 \%$ Aldrich; $0.13 \mathrm{~g}, 0.48 \mathrm{mmol})$, and MBA $(0.94 \mathrm{~g}, 6 \mathrm{mmol})$. The mixture was placed inside an oven at $60^{\circ} \mathrm{C}$ for $6 \mathrm{~h}$, and the resultant gel was cut into hemispherical pieces and kept under deionized water for 3 days. The water was changed at least twice over this time. The PMAA gel was then immersed inside an OEGMA solution for 5 days. The OEGMA solution comprised deionized water ( $60 \mathrm{~mL}, 3.3 \mathrm{~mol})$, OEGMA with a number average molar mass of $950 \mathrm{Da}$ (Aldrich; $12 \mathrm{~g}, 0.013 \mathrm{~mol}$ ), KPS (0.04 g, $0.15 \mathrm{mmol}$ ), and MBA (0.02 $\mathrm{g}, 0.13 \mathrm{mmol}$ ). After immersion, the gel was placed inside an oven at $60^{\circ} \mathrm{C}$ for $6 \mathrm{~h}$ after which it was stored under deionized water.

\section{Polymer brush preparation}

PDEAEMA brushes were grown from silicon substrates using surface-initiated atom-transfer radical polymerization (SI-ATRP). The silicon substrates used were purchased from Prolog Semicor and had the following characteristics: $50 \mathrm{~mm}$ diameter, p-type boron dopant, orientation (100) $\pm 1^{\circ}$, thickness $4.00 \pm$ $0.05 \mathrm{~mm}$. The cleaned silicon substrates were immersed for $30 \mathrm{~min}$ in a $2 \%(\mathrm{v} / \mathrm{v})$ solution of $(3-$ aminopropyl)triethoxysilane (APTES; 98\% Aldrich) in ethanol. The substrates were rinsed with ethanol, dried under nitrogen gas, and then annealed for $30 \mathrm{~min}$ at $120^{\circ} \mathrm{C}$. The surface was functionalized with initiator by immersing the APTES-coated silicon substrates in a mixture of triethylamine (99\% Aldrich; 0.41 $\mathrm{mL}, 3 \mathrm{mmol}$ ) and $\alpha$-bromoisobutyryl bromide (98\% Aldrich; $0.37 \mathrm{~mL}, 3 \mathrm{mmol}$ ) in dichloromethane (DCM) (99\% Aldrich; $100 \mathrm{~mL}, 1.4 \mathrm{~mol}$ ) for $30 \mathrm{~min}$ before being washed with ethanol and DCM and dried by a stream of nitrogen gas. For SI-ATRP, the following materials were used: 2-(diethyl amino)ethyl methacrylate (DEAEMA; 99\% Aldrich; $10.84 \mathrm{~mL}, 54.0 \mathrm{mmol}$ ), 2,2'-bipyridine (bipy; 99\% Aldrich; $0.39 \mathrm{~g}, 2.5$ mmol), copper(I) bromide ( $\mathrm{CuBr} ; 98 \%$ Aldrich; $0.12 \mathrm{~g} 0.9 \mathrm{mmol})$, copper(II) bromide ( $\mathrm{CuBr}_{2} ; 99 \%$ Aldrich; $0.06 \mathrm{~g}, 0.3 \mathrm{mmol})$, methanol $(8 \mathrm{~mL}, 0.20 \mathrm{~mol})$, and deionized water $(2 \mathrm{~mL}, 0.11 \mathrm{~mol})$. The DEAEMA monomer, methanol, and water were degassed separately inside round-bottom flasks for 30 min using nitrogen gas. The water and methanol were transferred into the monomer flask and then $\mathrm{CuBr}, \mathrm{CuBr}_{2}$, and bipy were added. The solution was stirred and degassed with nitrogen for $30 \mathrm{~min}$ and then transferred into a glass container with the silicon substrate and left at room temperature for $24 \mathrm{~h}$. Finally, the substrate was washed with methanol and ethanol, and then dried under a stream of nitrogen gas. The thickness of the dry brush layers was characterized using ellipsometry and determined to be between 70 and $80 \mathrm{~nm}$. 


\section{Adhesion measurements}

Measurements of the adhesion between PDEAEMA brushes and the SN and DN hydrogels were made using a mechanical tester (Stable Micro Systems Texture Analyser TA.XTplus). The tester comprises a mechanical probe used to fix a hemispherical hydrogel inside its plastic jacket and a platform on which the brush substrate is placed. The mechanical probe brought the hydrogel into contact with the polymer brush surface and a force of $0.5 \mathrm{~N}$ was applied for $2 \mathrm{~min}$ (no salt was added at this step). The force was then released (i.e. maintained at $0 \mathrm{~N}$ ) leaving the gel in contact with the surface of the polymer brush in its aqueous environment. $\mathrm{A} \mathrm{NaCl}$ solution of known concentration was then added into the water surrounding the gel-brush interface. A magnetic stirrer was used to stir the water very slowly so as to ensure mixing. The adhered gel-brush interface was then left inside the newly introduced $\mathrm{NaCl}$ solution for an hour. The gel was then retracted from the brush surface at a speed of $50 \mathrm{~mm} \mathrm{~min}{ }^{-1}$, with the maximum adhesion force $(F)$ and work done $(W$, the area under the force-distance curve during retraction) measured at the different salt concentrations. These measurements were performed at room temperature, $23 \pm 2^{\circ} \mathrm{C}$. Since the gel and brush were already adhered inside deionized water at $\mathrm{pH} 5.8$, the amount of this water was kept constant at $500 \mathrm{~mL}$ during all these experiments. The required molarities of the $\mathrm{NaCl}$ solutions were prepared in $500 \mathrm{~mL}$ of water, accounting for further dilution with the deionized water in which the gel and brush were adhered.

\section{RESULTS AND DISCUSSION}

\section{The Effect of Salt Solutions on Reversible Adhesion}

\section{Swelling Ratios of Hydrogels in Salt Solutions}

The influence of ionic strength on the swelling ratio $(Q)$ of both polyelectrolyte $S N$ and DN hydrogels was studied using different concentrations of $\mathrm{NaCl}$ solutions (between $1 \mathrm{mM}$ and $5 \mathrm{M}$ ) at a constant pH of 5.8. Many circular sheets (diameter $5 \mathrm{~cm}$ and thickness $5 \mathrm{~mm}$ ) of the PMAA (SN) and PMAA-POEGMA (DN) hydrogels were prepared to test their swelling ratios inside the different $\mathrm{NaCl}$ solutions. Each hydrogel was dried in a vacuum oven at $50^{\circ} \mathrm{C}$ for $5 \mathrm{~h}$ and then the mass of the dried gel $\left(M_{\text {dry }}\right)$ was measured and recorded. Thereafter, the dried flat sheets of the SN and DN hydrogels were immersed inside $\mathrm{NaCl}$ solutions of different concentrations and left for 5 days. The mass of the swollen gel $\left(M_{\text {swollen }}\right)$ was then measured and recorded. Finally, the swelling ratios $(Q)$ of both the SN and DN hydrogels were calculated at different $\mathrm{NaCl}$ solutions, where

$Q=M_{\text {swollen }} / M_{\text {dry }}$

The deswelling behaviour of the PMAA (SN) and PMAA-POEGMA (DN) hydrogels inside salt solutions as a function of increasing the $\mathrm{NaCl}$ concentration is shown in Figure 1. It was found that even a very small amount of $\mathrm{NaCl}(1 \mathrm{mM})$ resulted in the deswelling, $Q$, of both the $\mathrm{SN}$ and $\mathrm{DN}$ hydrogels decreasing to less than half of that inside deionized water (i.e. without the addition of salt). Specifically, the swelling ratio of the PMAA (SN) hydrogel was 13.6 inside deionized water (without adding salt) and 6.6 inside the $1 \mathrm{mM}$ 
$\mathrm{NaCl}$ solution. The swelling ratio of the PMAA-POEGMA (DN) hydrogel, meanwhile, was 6.5 inside deionized water (no added salt) and 2.7 inside the $1 \mathrm{mM} \mathrm{NaCl}$ solution.

On addition of $\mathrm{NaCl}$, both the PMAA (SN) and PMAA-POEGMA (DN) hydrogels deswelled until a concentration $0.01 \mathrm{M}$, above which $Q$ remained reasonably constant. However, above a concentration of $0.5 \mathrm{M}$, the swelling decreased further. It is likely that the initial decrease in swelling is due to the salt screening counterions and this is followed at greater concentrations by a salting-out effect.

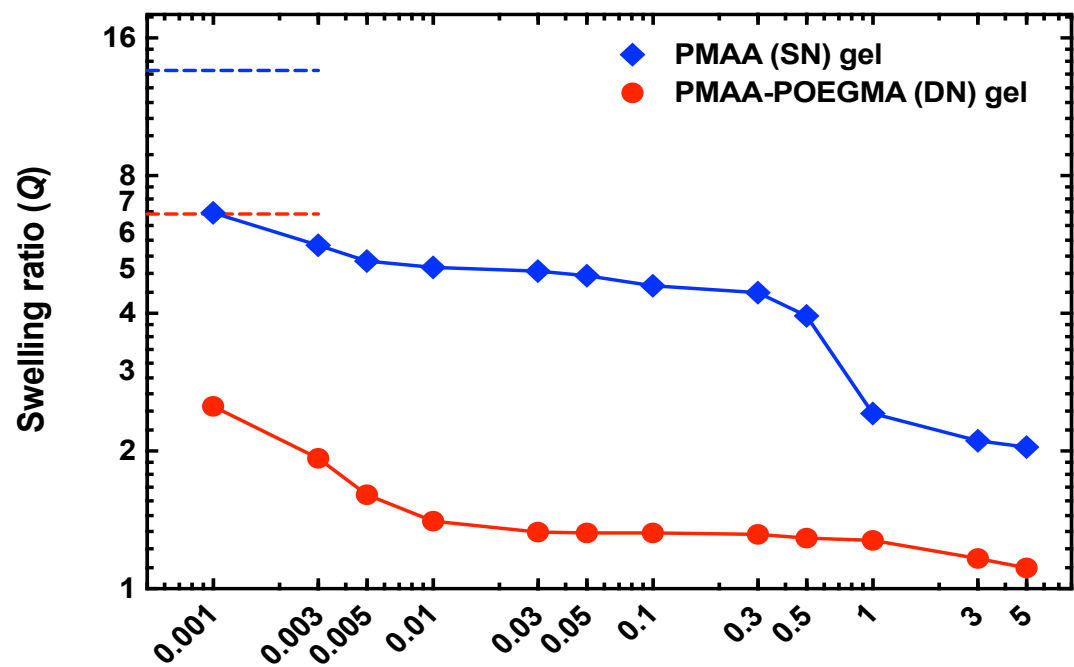

$\mathrm{NaCl}$ concentration (M)

FIGURE 1. The swelling ratio $(Q)$ of the PMAA (SN) hydrogel (blue diamonds) and the PMAA-POEGMA (DN) hydrogel (red circles) in aqueous solution as a function of $\mathrm{NaCl}$ concentration. The blue truncated horizontal line shows the swelling ratio of the SN gel in deionized water and the corresponding red line shows that for the DN gel

If the charges of either the hydrogel or the surface of the polymer brushes are sufficiently screened by the addition of $\mathrm{NaCl}$, the adhesive interactions at the gel-brush interface are likely to fail, resulting in a successful detachment for both polymers. The high degree of shrinkage in both networks of the SN and DN hydrogels indicates that there may be sufficient screening, and so it can be hypothesized that their adhesion to the polycationic PDEAEMA brushes can be eliminated or weakened by adding a large enough concentration of $\mathrm{NaCl}$ into the surrounding water. The results of the salt-sensitive adhesion experiment are presented in the following section.

\section{Reversible Adhesion Inside Salt Solutions}

Increasing the $\mathrm{NaCl}$ concentration in the water surrounding the SN and DN hydrogels leads to an eventual decrease in the polymeric network size as a result of the screening of their electrostatic charges among carboxylic groups. ${ }^{16}$ Pull-off adhesion experiments at the gel-brush interface were therefore conducted between the polyacid hydrogel of both of the PMAA (SN) and PMAA-POEGMA (DN) with the polybase (PDEAEMA) brush (75 $\mathrm{nm}$ thick) underwater as a function of increasing salt concentrations using the 
mechanical tester. The same range of molarity of the $\mathrm{NaCl}$ solutions as for the swelling experiments was used, varying from 0.001 to $5 \mathrm{M}$.

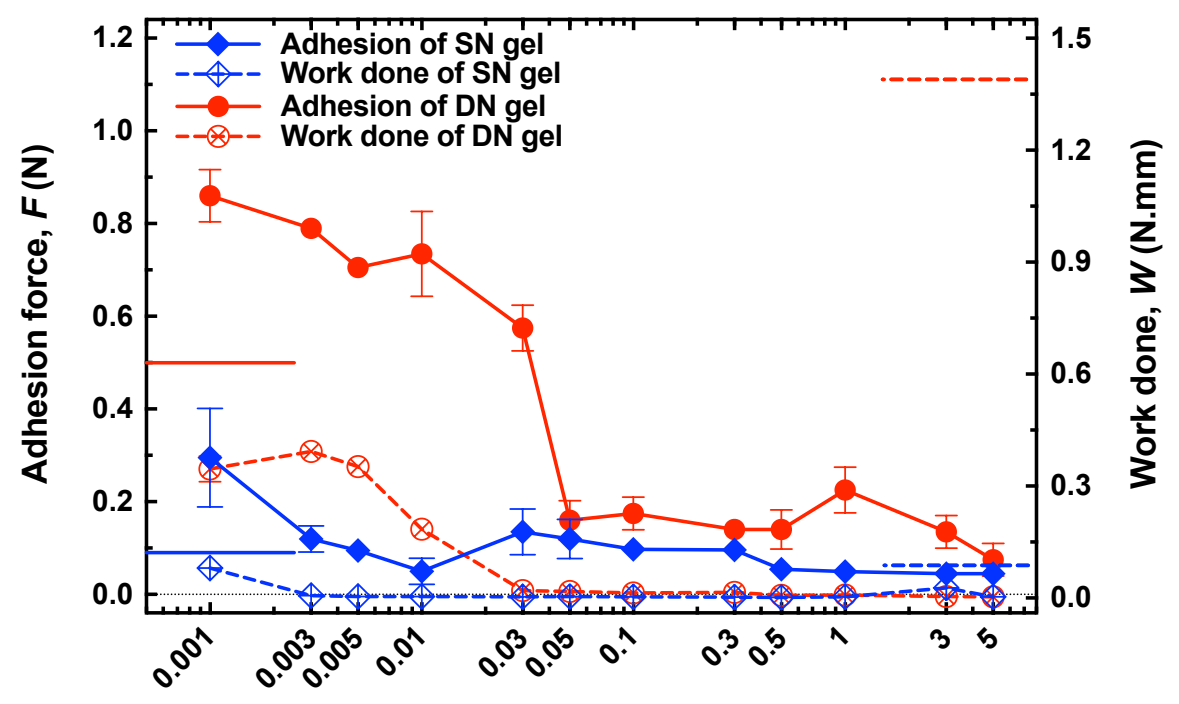

$\mathrm{NaCl}$ concentration (M)

FIGURE 2. The adhesion experiments for the PMAA (SN) hydrogel (blue diamonds) and the PMAA-POEGMA (DN) hydrogel (red circles) after adding the $\mathrm{NaCl}$ solution into their surrounding water at different concentrations. The filled symbols are related to the maximum adhesion forces while the crossed symbols refer to the work done, which were collected from force-distance curves. The truncated horizontal lines without the symbols correspond to the limiting values in the absence of added salt

The results of (aqueous) pull-off adhesion experiments for the PMAA (SN) and PMAA-POEGMA (DN) hydrogels, with the PDEAEMA brush as a function of added $\mathrm{NaCl}$ concentration into their surrounding water are shown in Figure 2. The adhesion force measurements of both SN and DN hydrogels unexpectedly increased after the addition of $\mathrm{NaCl}$ at a very low concentration of $0.001 \mathrm{M}$. Specifically, the normal adhesion force at the SN gel-PDEAEMA brush interface was $0.09 \mathrm{~N}$ inside deionized water at $\mathrm{pH}$ 5.8 (no added $\mathrm{NaCl}$ ), and this reached $0.29 \mathrm{~N}$ inside the $0.001 \mathrm{M} \mathrm{NaCl}$ solution. Similarly, the adhesion force at the DN gel-PDEAEMA brush interface inside deionized water was $0.5 \mathrm{~N}$, but it increased to $0.86 \mathrm{~N}$ after the addition of salt created a $0.001 \mathrm{M} \mathrm{NaCl}$ solution. Anomalous behaviour caused by the addition of a small amount of salt has been mentioned above for the swelling of hydrogels, ${ }^{16}$ but there have been other similarly unexpected results reported. For example, molecular diffusion (of dextran) inside a PMAA hydrogel increased on the addition of a small amount of $\mathrm{NaCl}$ (less than $0.05 \mathrm{M}$ ) relative to that in pure water. ${ }^{25}$ Further increases in salt caused the diffusion coefficient to decrease. It is not clear whether these results are specific to $\mathrm{NaCl}$; certainly the adhesion between oppositely charged brushes (PMAA and PDMAEMA) showed no such anomalous increase with increasing concentration of different potassium salts. ${ }^{23}$

The reason why the maximum adhesion force increased after adding $\mathrm{NaCl}$ solution at concentrations as low as $0.001 \mathrm{M}$ is still not clear, but the decrease in the work done inside the $0.001 \mathrm{M}$ solution does 
correlate with a decrease in the adhesion at the gel-brush interface due to the effect of the salt ions. A large work of adhesion for the force measured here would have required its persistence over a larger displacement (greater stretching), which would indicate an elastic contact. That the work of adhesion decreased might indicate that the failure might contain a significant contribution due to the polycation brush, which is not as elastic (stretchable) as the gel. It is certainly true that the behaviour of polyelectrolyte brushes has a rich physics, even at low salt concentration. ${ }^{26}$ The increased stretching of polyelectrolyte brushes on the introduction of a small amount of salt (osmotic swelling) may result in more interactions as the brush undergoes increased penetration of the gel. Nevertheless, the work done in respect of both of the PMAA (SN) and PMAA-POEGMA (DN) hydrogels decreased, compared to the value inside deionized water (at $\mathrm{pH}$ 5.8), after adding the $0.001 \mathrm{M} \mathrm{NaCl}$ salt solution. In the case of the adhesion of the PMAA (SN) hydrogel, the work done decreased from $0.13 \mathrm{~N} . \mathrm{mm}$ (in water) to $0.08 \mathrm{~N} . \mathrm{mm}$ in a $0.001 \mathrm{M}$ salt solution. The work done at the DN gel-PDEAEMA brush interface decreased significantly from $1.4 \mathrm{~N} . \mathrm{mm}$ (in water) to $0.35 \mathrm{~N} . \mathrm{mm}$ in $0.001 \mathrm{M} \mathrm{NaCl}$ solution.

(a)
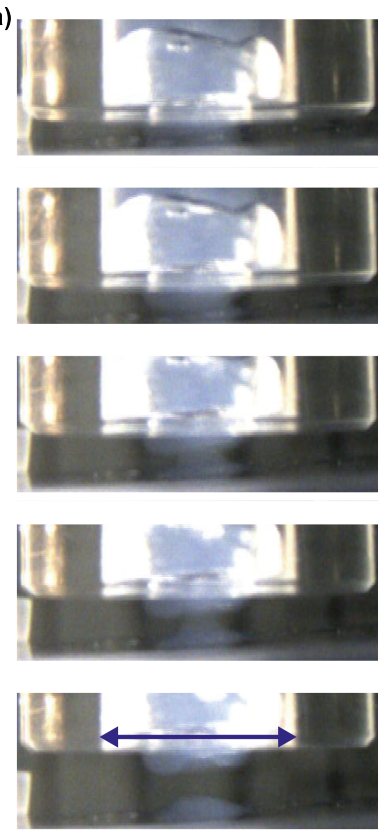

(b)
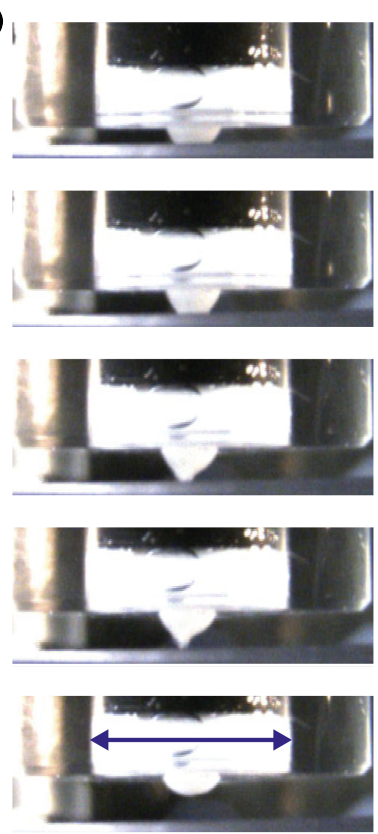

FIGURE 3. Detachment at the hydrogel-brush interfaces in a $5 \mathrm{M} \mathrm{NaCl}$ solution after initial immersion in deionized water for a (a) PMAA (SN) hydrogel and a (b) PMAA-POEGMA (DN) hydrogel. A cohesive failure was obtained with the SN hydrogel, while an adhesive failure occurred with the DN hydrogel. The solid arrows indicate the diameter of the mechanical probe of $10 \mathrm{~mm}$. The top images correspond to no applied force before retraction, with those below taken during retraction

After increasing the $\mathrm{NaCl}$ concentrations to $0.05 \mathrm{M}$ and above, however, the adhesion force and work done at the hydrogel-brush interface dropped significantly and became very weak, especially inside $3 \mathrm{M}$ and $5 \mathrm{M}$ solutions. Here, both $\mathrm{SN}$ and $\mathrm{DN}$ hydrogels shrunk in highly concentrated $\mathrm{NaCl}$ solutions. The larger reduction in adhesion measurements is likely to be due to polymer chains collapsing as a result of 
the screening of the electrostatic charges on the chains by salt ions. Charge shielding would also have aided in reducing the work done in detaching the hydrogel from the brush in all solutions.

Figure 3 shows the difference in the detaching process of the SN hydrogel and DN hydrogel from the PDEAEMA brush surface and also illustrates the failure type that occurred on the brush surface after detaching inside the $5 \mathrm{M} \mathrm{NaCl}$ solution. Although the adhesion measurements decreased significantly inside the highly concentrated $\mathrm{NaCl}$ solution of $5 \mathrm{M}$, it was found that a cohesive failure was still associated with the adhesion of the PMAA (SN) hydrogel (see Figure 3a), while an adhesive failure was obtained with the PMAA-POEGMA (DN) (see Figure 3b). These cohesive and adhesive failures resulted from the difference in the mechanical strength of the SN and DN hydrogels, since the soft SN gel had a much lower crosslinking density and a weaker mechanical strength compared to the highly crosslinked DN gel.

\section{Comparing the Effect of Salt and pH Solutions}
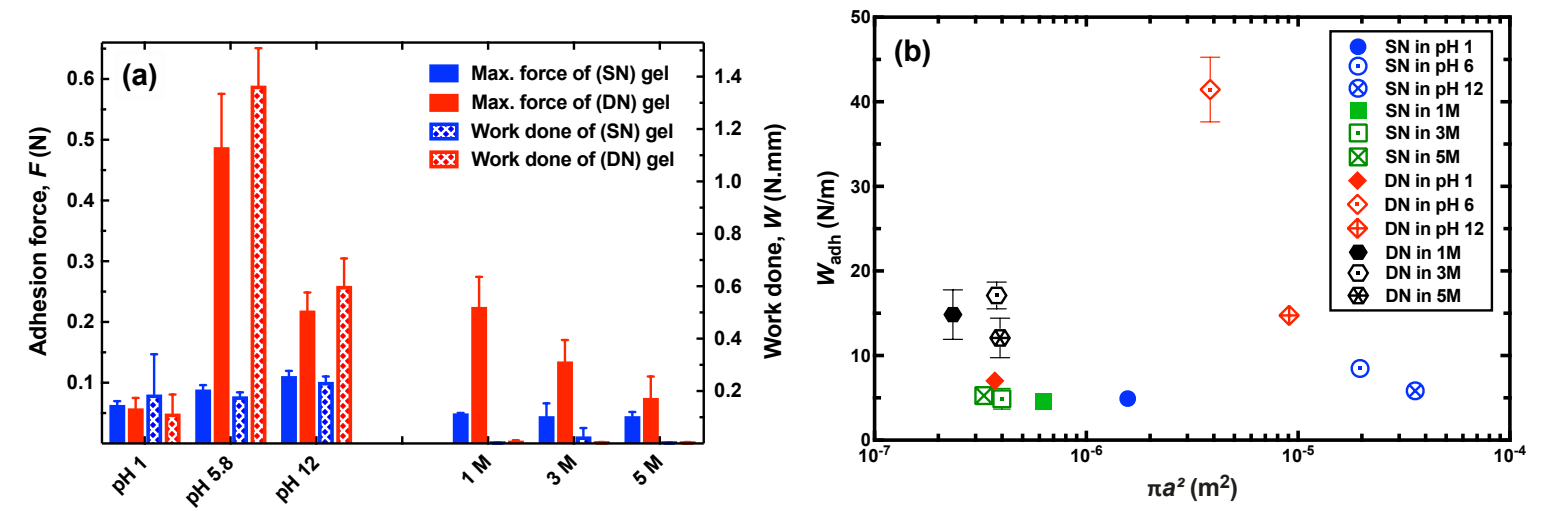

FIGURE 4. (a) Maximum adhesion force and work done at the interface between SN (blue columns) and DN (red columns) hydrogels and polybase brushes in solutions of different $\mathrm{pH}$ (left) and different $\mathrm{NaCl}$ concentration (right). (b) Work of adhesion calculated using the JKR method as a function of contact area corresponding to the adhesion couples shown in (a)

Adding $\mathrm{NaCl}$ solutions to switch the adhesion off at the gel-brush interface is different from using a strong acid (or base) solution ${ }^{3}$ in a number of respects. Figure 4a illustrates a comparison between the different effects of the salt and $\mathrm{pH}$ solutions on the adhesion of the PMAA (SN) and PMAA-POEGMA (DN) hydrogels with the PDEAEMA brush underwater. Here the data are shown for the maximum adhesive force $(F)$ and the work done $(W)$ for both SN and DN hydrogels with the polybase brush in deionized water (pH 5.8) and also in water at $\mathrm{pH} 1$ and 12 and salt solutions at $1 \mathrm{M}, 3 \mathrm{M}$ and $5 \mathrm{M} \mathrm{NaCl}$.

Both the experimental adhesion studies for $\mathrm{pH}$ and salt solutions had the same experimental factors in terms of the applied force $(0.5 \mathrm{~N})$ at the gel-brush interface, contact time $(2 \mathrm{~min})$ and retraction speed at which the hydrogel was detached from the surface of the polymer brush $(50 \mathrm{~mm} / \mathrm{min})$. Prior to detachment, they were brought together in deionized water before the solution properties were changed $(\mathrm{pH}$ or $\mathrm{NaCl})$. The time for leaving the adhered gel-brush interface inside the newly introduced $\mathrm{pH}$ or salt solution was the same $(1 \mathrm{~h})$. 
The best adhesion results were obtained for both gels with the brush surface in deionized water at pH 5.8. In contrast, the maximum adhesive force for both SN and DN hydrogels decreased compared to those in the $\mathrm{pH} 1$ and $\mathrm{NaCl}$ solutions.

Given the large changes in gel volume as the external environment changes, it is helpful to consider the results in terms of an intensive parameter. To this end, the thermodynamic work of adhesion of both SN and DN gels was calculated from the contact area at the interface between the hydrogel and the brush surface using the standard JKR formalism, ${ }^{27}$

$W_{\text {adh }}=\frac{2 F}{3 \pi R}$

where $R$ is the radius of the gel. These results are presented in Figure $4 \mathrm{~b}$ as a function of the contact area.

The adhesion of the SN hydrogel at pH 12 (Figure 4a, both the pull-off force and work done) increased compared to that at $\mathrm{pH} 6$. This result is surprising because there is no evidence of this behaviour in the contact between two brushes, ${ }^{12}$ and so any explanation must be specific to the hydrogel-brush couple. The JKR presentation in Figure $\mathbf{4 b}$ does not exhibit this trend, and so it is probable therefore that the increased adhesion is due to the dramatically increased swelling of the gel resulting in a greater contact area, which more than compensates for a reduction in the areal density of electrostatic interactions. The work of adhesion, $W_{\text {adh }}$, is very large and reflects the large stresses in these systems. ${ }^{13}$ It is also likely that some of the gels have undergone plastic deformation, under which circumstances Equation (2) is not an accurate measure of the thermodynamic adhesion.

These results show that $\mathrm{pH}$-switchable adhesion is much more effective than the use of a salt solution, even at the largest $\mathrm{NaCl}$ concentration. Nevertheless, the work done in detaching the hydrogels from the brush surface inside the $\mathrm{NaCl}$ solutions was almost zero, confirming earlier work that salt can be used for switchable adhesive applications. ${ }^{7}$ It is possible that salt remains trapped in the gel, which may affect the adhesion. Certainly, a problem of precipitation of salt on polyelectrolyte brushes has been suggested to explain experimental results in the case of the adhesion between identical polyzwitterionic brushes. ${ }^{10}$

\section{CONCLUSIONS}

The effects of increasing salt concentrations on the swelling ratios of the PMAA (SN) and PMAA-POEGMA (DN) hydrogels have been discussed. It was found that both SN and DN hydrogels shrank sharply in a very dilute $\mathrm{NaCl}$ solution, decreasing to less than half that of the swelling ratios that were measured in deionized water (at $\mathrm{pH} 5.8$, in the absence of salt). As the concentration of the $\mathrm{NaCl}$ increased, the swelling ratio of SN and DN hydrogels decreased further. Significant deswelling, however, was obtained for both $\mathrm{SN}$ and DN hydrogels inside $\mathrm{NaCl}$ solutions with concentrations greater than $0.5 \mathrm{M}$. The impact of salt concentration on the adhesion of both SN and DN hydrogels with the polybase brush was also investigated. It was found that the adhesive force at the gel-brush interface significantly increased after adding a very small amount of the $\mathrm{NaCl}$ salt $(0.001 \mathrm{M})$ into the surrounding water. The work done in detaching the hydrogel from the brush surface was somewhat less than the work done inside deionized 
water, however, confirming that the adhesive interactions at the interface were reduced. On the other hand, the gel-brush adhesion was notably affected after raising the concentration of the $\mathrm{NaCl}$ solution above $0.5 \mathrm{M}$, as shown by the clear reduction obtained in respect of both the adhesive force and work done. As in earlier work, a cohesive failure was observed after detaching the PMAA (SN) hydrogel from the polycation brush surface, while an adhesive failure occurred with the adhesion of the PMAA-POEGMA (DN) hydrogel.

\section{GRAPHICAL ABSTRACT}

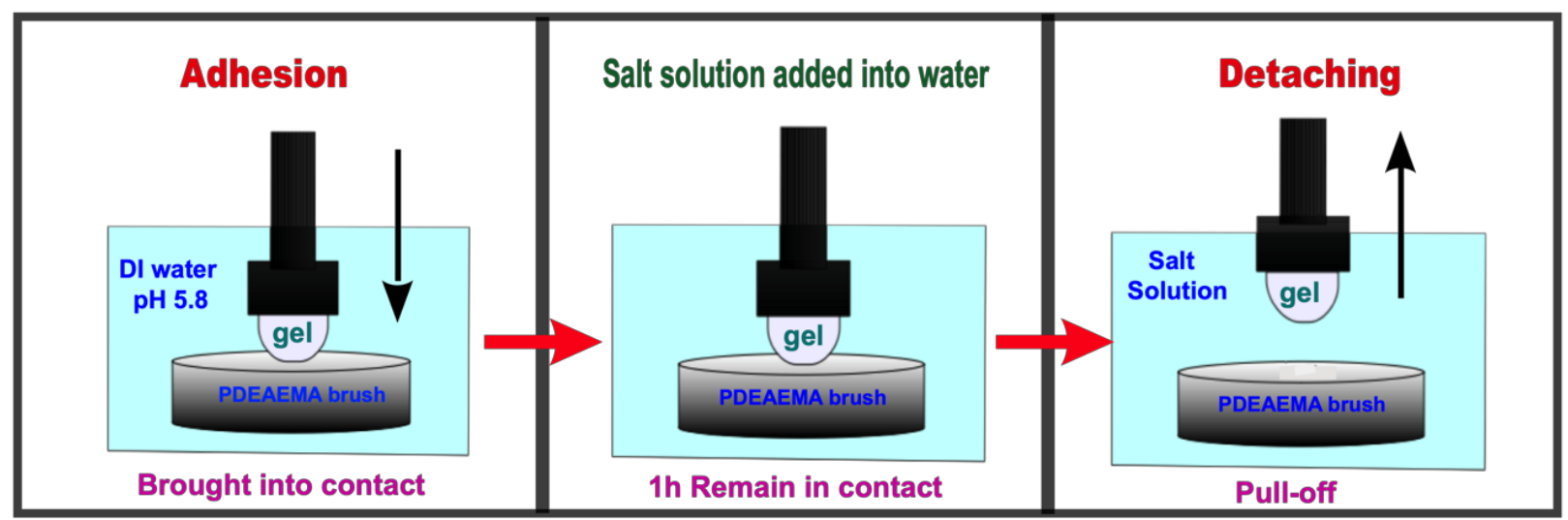

\section{REFERENCES AND NOTES}

1. Banea, M. D.; da Silva, L. F. M.; Campilho, R. D. S. G.; Sato, C., J. Adhes. 2013, 90, 16-40.

2. Hall, A. R.; Geoghegan, M., Rep. Prog. Phys. 2018, 81, 036601.

3. Alfhaid, L.; Seddon, W. D.; Williams, N. H.; Geoghegan, M., Soft Matter 2016, 12, 5022-5028.

4. La Spina, R.; Tomlinson, M. R.; Ruiz-Pérez, L.; Chiche, A.; Langridge, S.; Geoghegan, M., Angew. Chem. Int. Ed. 2007, 46, 6460-6463.

5. Shuttleworth, P. S.; Clark, J. H.; Mantle, R.; Stansfield, N., Green Chem. 2010, 12, 798-803.

6. Sudre, G.; Olanier, L.; Tran, Y.; Hourdet, D.; Creton, C., Soft Matter 2012, 8, 8184-8193.

7. $\quad$ Kobayashi, M.; Terada, M.; Takahara, A., Soft Matter 2011, 7, 5717-5722.

8. Collett, J.; Crawford, A.; Hatton, P. V.; Geoghegan, M.; Rimmer, S., J. R. Soc. Interface 2007, 4, 117-126.

9. Gurney, R. S.; Dupin, D.; Nunes, J. S.; Ouzineb, K.; Siband, E.; Asua, J. M.; Armes, S. P.; Keddie, J. L., ACS Appl. Mater. Interfaces 2012, 4, 5442-5452.

10. Kobayashi, M.; Takahara, A., Polym. Chem. 2013, 4, 4987-4992.

11. Rolli, C. G.; Nakayama, H.; Yamaguchi, K.; Spatz, J. P.; Kemkemer, R.; Nakanishi, J., Biomaterials 2012, 33, 2409-2418.

12. Raftari, M.; Zhang, Z. J.; Carter, S. R.; Leggett, G. J.; Geoghegan, M., Macromolecules 2015, 48, 6272-6279.

13. Alfhaid, L.; La Spina, R.; Tomlinson, M. R.; Hall, A. R.; Seddon, W. D.; Williams, N. H.; Cousin, F.; Gorb, S.; Geoghegan, M., J. Adhes. 2018, 94, 58-76.

14. Creton, C.; Ciccotti, M., Rep. Prog. Phys. 2016, 79, 046601.

15. Gong, J. P., Soft Matter 2010, 6, 2583-2590.

16. Ostroha, J.; Pong, M.; Lowman, A.; Dan, N., Biomaterials 2004, 25, 4345-4353.

17. Zhang, J.; Peppas, N. A., Macromolecules 2000, 33, 102-107. 
18. Kobayashi, M.; Mitamura, K.; Terada, M.; Yamada, N. L.; Takahara, A., J. Phys.: Conf. Ser. 2011, 272, 012019.

19. Parnell, A. J.; Martin, S. J.; Dang, C. C.; Geoghegan, M.; Jones, R. A. L.; Crook, C. J.; Howse, J. R.; Ryan, A. J., Polymer 2009, 50, 1005-1014.

20. Tran, Y.; Auroy, P.; Lee, L.-T., Macromolecules 1999, 32, 8952-8964.

21. Lego, B.; Skene, W. G.; Giasson, S., Macromolecules 2010, 43, 4384-4393.

22. Zhulina, E. B.; Birshtein, T. M.; Borisov, O. V., Macromolecules 1995, 28, 1491-1499.

23. Raftari, M.; Zhang, Z. J.; Carter, S. R.; Leggett, G. J.; Geoghegan, M., Tribol. Lett. 2018, 66, 11.

24. Naficy, S.; Razal, J. M.; Whitten, P. G.; Wallace, G. G.; Spinks, G. M., J. Polym. Sci. B: Polym. Phys. 2012, 50, 423-430.

25. AL-Baradi, A. M.; Mears, M.; Jones, R. A. L.; Geoghegan, M., J. Polym. Sci. B: Polym. Phys. 2012, 50, 1286-1292.

26. Rühe, J.; Ballauff, M.; Biesalski, M.; Dziezok, P.; Gröhn, F.; Johannsmann, D.; Houbenov, N.; Hugenberg, N.; Konradi, R.; Minko, S.; Motornov, M.; Netz, R. R.; Schmidt, M.; Seidel, C.; Stamm, M.; Stephan, T.; Usov, D.; Zhang, H., Adv. Polym. Sci. 2004, 165, 79-150.

27. Johnson, K. L.; Kendall, K.; Roberts, A. D., Proc. R. Soc. London A 1971, 324, 301-313. 